Journal for ImmunoTherapy of Cancer

\title{
Identification of neoantigen-reactive $T$ lymphocytes in the peripheral blood of a patient with glioblastoma
}

\author{
Vid Leko (D) , ${ }^{1}$ Gal Cafri, ${ }^{2}$ Rami Yossef, ${ }^{1}$ Biman Paria, ${ }^{3}$ Victoria Hill, ${ }^{1}$ \\ Devikala Gurusamy, ${ }^{1}$ Zhili Zheng, ${ }^{1}$ Jared J Gartner, ${ }^{1}$ Todd D Prickett, ${ }^{1}$ \\ Stephanie L Goff (D) , ${ }^{1}$ Paul Robbins (D) , ${ }^{1}$ Yong-Chen Lu, ${ }^{1}$ Steven A Rosenberg ${ }^{1}$
}

To cite: Leko V, Cafri G, Yossef $\mathrm{R}$, et al. Identification of neoantigen-reactive $T$ lymphocytes in the peripheral blood of a patient with glioblastoma. Journal for ImmunoTherapy of Cancer 2021;9:e002882. doi:10.1136/ jitc-2021-002882

\section{- Additional supplemental} material is published online only. To view, please visit the journal online (http://dx.doi.org/10. 1136/jitc-2021-002882).

Accepted 04 June 2021

\section{Check for updates}

(c) Author(s) (or their employer(s)) 2021. Re-use permitted under CC BY-NC. No commercial re-use. See rights and permissions. Published by BMJ.

${ }^{1}$ Surgery Branch, National Cancer Institute, Bethesda, Maryland, USA

${ }^{2}$ Sheba Medical Center, Ramat Gan, Israel

${ }^{3}$ Program Coordination and Referral Branch, National Cancer Institute, Bethesda, Maryland, USA

Correspondence to DrVid Leko; vid.leko@nih.gov

\section{ABSTRACT}

The adoptive transfer of naturally occurring $T$ cells that recognize cancer neoantigens has led to durable tumor regressions in select patients with cancer. However, it remains unknown whether such T cells can be isolated from and used to treat patients with glioblastoma, a cancer that is refractory to currently available therapies. To answer this question, we stimulated patient blood-derived memory T cells in vitro using peptides and minigenes that represented point mutations unique to patients' tumors (ie, candidate neoantigens) and then tested their ability to specifically recognize these mutations. In a cohort of five patients with glioblastoma, we found that circulating $\mathrm{CD}^{+}$memory $\mathrm{T}$ cells from one patient recognized a cancer neoantigen harboring a mutation in the EED gene $\left(E E D^{\mathrm{H} 189 \mathrm{~N}}\right)$ that was unique to that patient's tumor. This finding suggests that neoantigen-reactive T cells could indeed be isolated from patients with glioblastoma, thereby providing a rationale for further efforts to develop neoantigen-directed adoptive $T$ cell therapy for this disease.

\section{INTRODUCTION}

Glioblastoma, the most common primary brain malignancy in adults, remains essentially incurable with the standard therapy, which includes surgery, radiotherapy and chemotherapy. Given that only $7.2 \%$ of patients survive 5 years postdiagnosis, new therapeutic approaches are urgently needed. ${ }^{1}$

In recent clinical studies, immunotherapy with checkpoint inhibitors, ${ }^{2}$ cancer vaccines $^{3-7}$ and CAR T cells ${ }^{8}$ has largely failed to induce tumor regressions in patients with glioblastoma. A single case of a transient complete response following the intracranial administration of anti-IL13R $\alpha 2$ CAR T cells was a notable exception. ${ }^{9} \mathrm{Such}$ a low response rate to immunotherapy has been attributed to the paucity of targetable tumor antigens, as well as to the presence of a strongly immunosuppressive tumor microenvironment, neuroanatomical constraints (ie, the blood-brain barrier) and marked tumor heterogeneity. ${ }^{10}$
Despite these discouraging results, several reports have indicated that glioblastoma may still be susceptible to an immune attack by endogenous $\mathrm{T}$ cells. For instance, in two patients whose tumors exhibited excessively high mutational burden due to a mismatch repair deficiency, immune checkpoint inhibition resulted in durable tumor regressions. ${ }^{11}$ In other studies, checkpoint inhibitors administered before brain surgery were found to promote tumor infiltration by T cells. ${ }^{12} 13$

Endogenous $\mathrm{T}$ cells can mediate an antitumor immune attack by recognizing cancer neoantigens, the proteins that are predominantly encoded by genes harboring point mutations unique to patients' tumors. Neoantigen-reactive $\mathrm{T}$ cells can be isolated from patients with various cancer types and, when expanded and used for adoptive cell therapy, can lead to durable tumor regressions. ${ }^{14}$ However, it remains unknown whether this form of immunotherapy can be used to treat glioblastoma, because naturally occurring neoantigen-reactive $\mathrm{T}$ cells have not yet been isolated from patients with this disease.

In this study, we tested whether $\mathrm{T}$ cells from patients with glioblastoma could recognize neoantigens unique to patients' autologous tumors. To this end, five patients with refractory or relapsed glioblastoma, who had been enrolled on an anti-EGFRvIII CAR T protocol, ${ }^{15}$ were selected based on the availability of blood and archived tumor specimens. Next, their tumors were subjected to whole exome sequencing (WES), and the resulting data were used to construct screening libraries that represented tumorspecific point mutations (ie, candidate neoantigens). Finally, memory $\mathrm{T}$ cells were isolated from patients' blood and, following a stimulation in vitro, tested for recognition of these candidates. 


\section{MATERIALS AND METHODS WES and RNA-seq}

Genomic DNA was extracted from formalin-fixed, paraffin-embedded (FFPE) tumors using a column-based truXTRAC FFPE total NA kit (Covaris, Woburn, Massachusetts, USA). DNA and RNA from matched normal blood, as well as from the homogenized fresh tumor (Patient $1)$, were extracted using the Allprep DNA/RNA Miniprep extraction kit (QIAGEN, Germantown, Maryland, USA). Following WES and RNA-seq library preparation and sequencing, tumor-specific single nucleotide variants (SNVs) and short insertions and deletions (INDELs) were identified as described previously. ${ }^{16}$ Where applicable, mutation clonality analysis was performed on WES data using PyClone, ${ }^{17}$ based on tumor purity and copy number estimates generated using Sequenza. ${ }^{18}$

\section{Screening libraries}

Mutation data were used to generate tandem minigene (TMG) and peptide pool (PP) screening libraries. TMGs were designed by linking up to 12 minigenes, each encoding either a non-synonymous point mutation (with each mutated amino acid flanked bilaterally by 12 wild type (WT) amino acids) or a frameshift INDEL (with 12 WT amino acids preceding the new reading frame, which terminated at the next stop codon). Their sequences were cloned into pcRNA2SL plasmids and transcribed into RNA, as described previously. ${ }^{16}$

PPs were composed of up to 12 individual crude-grade 25-mer peptides, the sequence of which corresponded to the minigenes. Peptides purified with high-performance liquid chromatography (HPLC) were used in validation experiments. All peptides were obtained from GenScript (Piscataway, New Jersey, USA).

\section{Antigen presenting cells (APCs)}

Autologous dendritic cells (DCs) and B cells were used as APCs. They were generated by purifying $\mathrm{CD} 14^{+}$and $\mathrm{CD}_{19}{ }^{+}$peripheral blood mononuclear cells (PBMCs) using magnetic microbeads (BD Biosciences, San Jose, California, USA) and culturing them as described in Refs. 14 and 19 , respectively.

\section{In vitro stimulation (IVS) of memory T cells}

IVS was performed following a previously described approach. ${ }^{16}$ Briefly, $0.5-1 \times 10^{6}$ memory $\mathrm{T}$ cells, isolated based on CD62L and CD45RO expression (figure 1A), were cocultured (ie, stimulated) in 4:1 ratio with DCs. TMG-electroporated DCs were used to stimulate memory $\mathrm{CD}^{+}$cells, while PP-pulsed DCs were used to stimulate memory $\mathrm{CD}^{+}$and-if sample size permitted- memory $\mathrm{CD}^{+}$cells. This approach was supported by a recent publication that demonstrated the superior ability of TMGs and PPs to elicit detectable antigen recognition from $\mathrm{CD} 8^{+}$and $\mathrm{CD} 4^{+}$cells, respectively. ${ }^{20}$

Initial cocultures were performed in 48-well plates, using media supplemented with IL-21 $(30 \mathrm{ng} / \mathrm{mL})$. On days 3,6 and 9, cells were serially expanded into larger-format wells, based on their growth rate. During each expansion, fresh media containing IL-21 (60 ng/ $\mathrm{mL})$ and IL-2 $(6000 \mathrm{IU} / \mathrm{mL})$ was added in $1: 1 \mathrm{~V} / \mathrm{V}$ ratio.

On day 12, expanded T cells were cocultured with DCs or B cells loaded with the TMGs or PPs used for initial stimulation. The next day, T cells with the highest expression of $4-1 \mathrm{BB}$ and OX-40 were sorted and subjected to a rapid expansion protocol using irradiated allogeneic feeders and anti-CD3 antibody (clone OKT3; Affymetrix, San Diego, California, USA). Expanded cells were then tested for the recognition of patient's TMGs or PPs (see below). Concurrently, IVS with CEFX (JPT Peptide Technologies, Berlin, Germany), a mix of virally derived peptides, was performed as a control.

\section{Assessment of neoantigen recognition}

Neoantigen recognition was evaluated by preforming overnight $\mathrm{T}$ cell cocultures with APCs, as described previously. ${ }^{16}$ Prior to coculturing, the APCs were either pulsed for 2 hours with individual peptides or PPs (final concentration of $10 \mu \mathrm{M}$ ) or were electroporated with TMG or full-gene RNA $\left(0.5-1 \mu \mathrm{g}\right.$ RNA $/ 1 \times 10^{5}$ cells) using a Neon Transfection System (Life Technologies, Carlsbad, California, USA). T cell activation was assessed by measuring the production of IFN- $\gamma$ or of multiple cytokines, or by measuring upregulation of 4-1BB and OX40 on T cells using flow cytometry.

IFN- $\gamma$ production was measured by either ELISA, which was performed using a designated kit (ThermoFisher Scientific, Waltham, Massachusetts, USA), or by ELISPOT, which was performed using appropriate capture and detection antibodies (both from Mabtech, Cincinnati, Ohio, USA). Multicytokine analysis was performed using a customized U-PLEX kit (Meso Scale Diagnostics, Rockville, Maryland, USA).

\section{Flow cytometry}

For all experiments, cells were stained with antibodies diluted in $\mathrm{PBS} / 0.5 \%$ FBS in $1: 50 \mathrm{~V} / \mathrm{V}$ ratio at $4^{\circ} \mathrm{C}$ for $30 \mathrm{~min}$. The antibodies were obtained from BD Biosciences: CD3 (clone SK7), CD8 (SK1), CD4 (SK3), CD62L (DREG-56), CD45RO (UCHL1), 4-1BB (4B4-1) and OX40 (ACT35). Flow cytometry was performed on FACS Canto I cell analyzer (BD Biosciences). Cell sorting was performed on the SH800 sorter (Sony Biotechnology, San Jose, California, USA). Data were analyzed using FlowJo 10.2 software (TreeStar, Ashland, Oregon, USA).

\section{Identification, synthesis and transduction of $T$ cell receptors (TCRs)}

PP2-reactive $\mathrm{T}$ cells from Patient 1 were cocultured for 4 hours with B cells pulsed with dimethyl sulfoxide (DMSO) or PP2 and then subjected to an IFN- $\gamma$ capture assay (Miltenyi, Auburn, California, USA). Next, single IFN- $\gamma^{+} \mathrm{T}$ cells were sorted into a 96-well microplate, which was subjected to a previously outlined TCR sequencing protocol. ${ }^{21}$ TCR synthesis and transduction into allogeneic PBMCs was performed as described previously. ${ }^{16}$ 
A

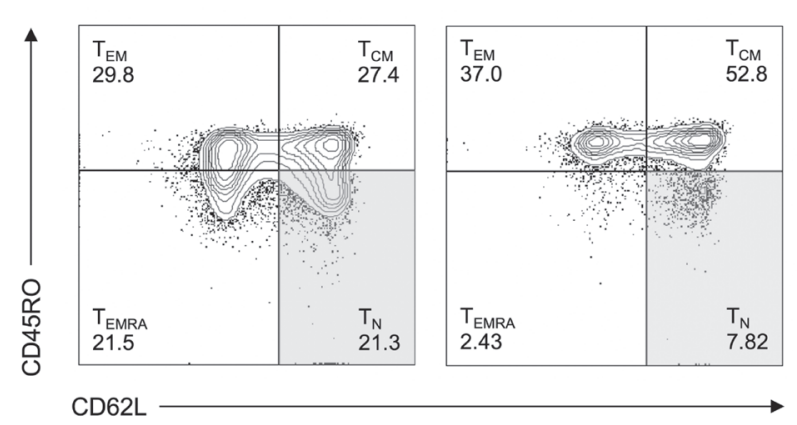

B

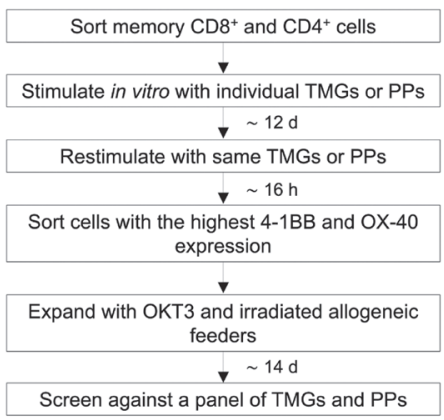

C

\begin{tabular}{|llllll|}
\hline ○ TMG1 & $\square$ TMG4 & $\Delta$ TMG7 & $\ominus$ PP1 & $\boldsymbol{\square}$ PP4 & $\oplus$ CEFX \\
$\odot$ TMG2 & $\square$ TMG5 & + Mock & $\ominus$ PP2 & $\Delta$ PP5 & * DMSO \\
$\otimes$ TMG3 & $\boldsymbol{\otimes}$ TMG6 & & $\square$ PP3 & $\boldsymbol{\nabla}$ PP6 & $\times$ PMA \\
\hline
\end{tabular}
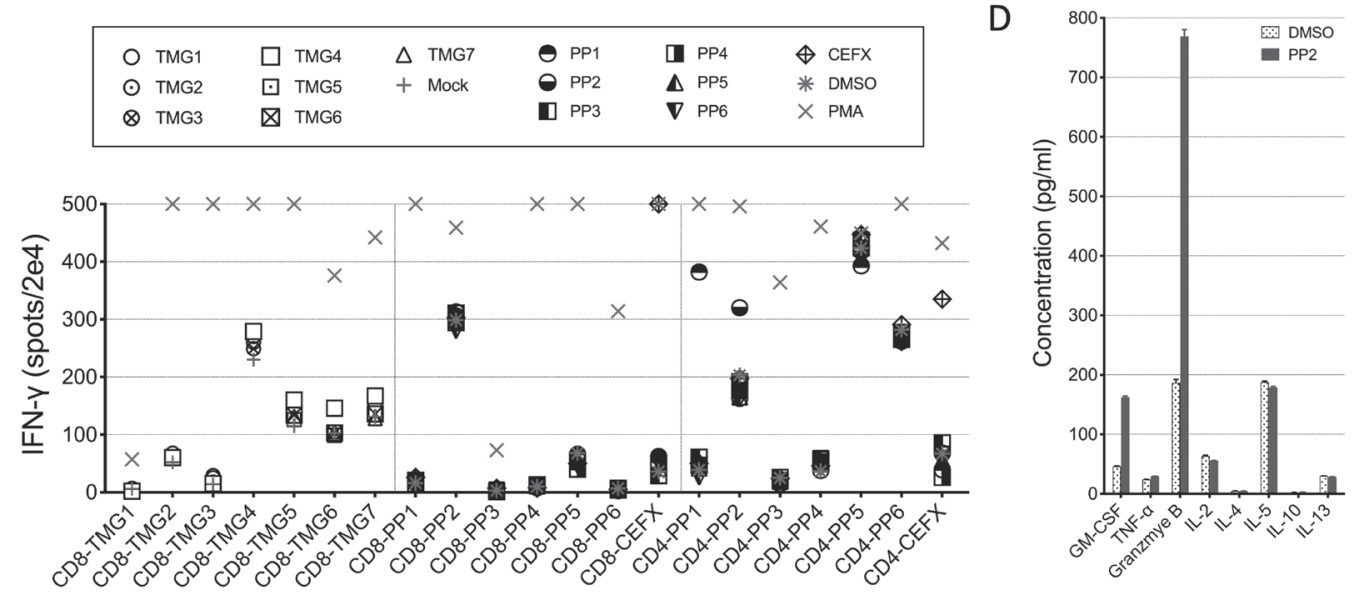

Figure 1 In vitro stimulated memory $\mathrm{CD} 4^{+} \mathrm{T}$ cells from Patient 1 screened positive for recognition of mutant 25-mer peptide pools. (A) An example of memory T cell sorting from patients' PBMCs. Each sorted CD8 ${ }^{+}$and $C D 4^{+}$group (unshaded areas) comprised of central memory $\left(\mathrm{T}_{\mathrm{CM}} ; \mathrm{CD} 62 \mathrm{~L}^{+} \mathrm{CD} 45 \mathrm{RO}^{+}\right)$, effector memory $\left(\mathrm{T}_{\mathrm{EM}} ; \mathrm{CD} 62 \mathrm{~L}^{-} \mathrm{CD} 45 \mathrm{RO}^{+}\right)$and effector memory reexpressing CD45RA ( $\mathrm{T}_{\text {EMRA }}$; $\mathrm{CD} 6 \mathrm{~L}^{-} \mathrm{CD} 45 \mathrm{RO} \mathrm{C}^{-}$) subpopulations. Contour plots were gated on live $\mathrm{CD}^{+}$cells. (B) Experimental outline describing IVS of memory T cells with TMGs and PPs that represented cancer-specific mutations. Memory CD8 ${ }^{+} \mathrm{T}$ cells were stimulated with TMGs and-cell numbers permitting-PPs; memory CD4 ${ }^{+}$cells were stimulated with PPs. A pool of viral peptides (CEFX) was used alongside PPs as a control. (C) Memory CD8 ${ }^{+}$and $\mathrm{CD} 4^{+}$cells, stimulated with individual TMGs or PPs (indicated on the $x$ axis), were screened for recognition of a panel of TMGs or PPs (boxed legend). Results of IFN- $\gamma$ ELISPOT are depicted. Sterile water alone (Mock) and DMSO were used as negative controls for TMG and PP testing, respectively. PMA/ionomycin (PMA) was used as a positive control. (D) Supernatants of PP2-stimulated CD4 ${ }^{+} \mathrm{T}$ cell cocultures with DMSO and PP2 were harvested from the IFN- $\gamma$ ELISPOT plate in (C) and were subjected to a multiplex assay for GM-CSF, TNF- $\alpha$, granzyme B, IL-2, IL-4, IL-5, IL-10 and IL-13. Data represent average reads from duplicate coculture wells; error bars represent SD. IFN- $\gamma$ concentration could not be accurately assessed in the multiplex assay due to sequestration of this cytokine on the IFN- $\gamma$ ELISPOT plate. IVS, in vitro stimulation; PBMC, peripheral blood mononuclear cell; PP, peptide pool; TMG, tandem minigene.

\section{TCR deep sequencing}

TCR-Vß deep sequencing was performed on genomic DNA extracted from the sorted memory $\mathrm{T}$ cells by immunoSEQ (Adaptive Technologies, Seattle, Washington, USA). The data were analyzed using the immunoSEQ Analyzer 3.0.

\section{Determination of MHC restriction element and assessment of EED $^{\mathrm{H} 189 \mathrm{~N}}$ gene recognition}

The major histocompatibility complex (MHC)-II alleles expressed by Patient 1 were synthesized and cloned into pcDNA3.1 plasmids (GeneOracle, Santa Clara, California, USA). Next, COS7 cells were cotransfected with combinations of individual plasmids and then pulsed with WT or mutant 25-mer $\mathrm{EED}^{\mathrm{H} 189 \mathrm{~N}}$ peptide for 2 hours. Following an overnight coculture with TCR-transduced T cells, IFN- $\gamma$
ELISA was performed. To assess EED gene recognition, cotransfection with plasmids encoding the WT or mutant EED genes was performed instead of peptide pulsing.

\section{Statistical analyses}

Statistical analyses were performed on GraphPad Prism 7.0 software (GraphPad Software, La Jolla, California, USA). When applicable, data were expressed as mean \pm SD.

\section{RESULTS}

\section{Study patients}

The five patients in this study were referred to the NIH for management of EGFRvIII-positive glioblastoma (online supplemental table 1). The PBMCs used for neoantigen screening were obtained via leukapheresis, which was 
performed before the administration of anti-EGFRvIII CAR T cells.

Concurrently, FFPE tumor biopsies were obtained from the referring institutions and were subjected to WES. For Patient 1 , a freshly resected tumor sample, obtained after CAR T cell administration, was added to the analysis. In the entire cohort, WES revealed between 71 and 115 nonsynonymous mutations per tumor (online supplemental table 1), in accordance with a previous report. ${ }^{22}$ These mutations, which consisted predominantly of SNVs, with a minor fraction of INDELs, were incorporated into TMG and PP screening libraries (online supplemental table 2).

\section{Memory T cells from Patient 1 screened positive for recognition of peptide pools representing candidate neoantigens}

To explore whether neoantigen-reactive $\mathrm{T}$ cells can be isolated from patients with glioblastoma, we used an IVSbased method that previously resulted in enrichment of such cells from the blood of patients with gastrointestinal malignancies. ${ }^{16}$ To this end, memory $\mathrm{CD}^{+}$and $\mathrm{CD}^{+} \mathrm{T}$ cells were first sorted from patients' PBMCs based on CD62L and CD45RO expression (figure 1A, online supplemental table 3 ). The naive $\mathrm{T}$ cells were excluded from this procedure in an attempt to assess only the physiologically relevant anticancer $\mathrm{T}$ cell responses. Next, sorted memory $\mathrm{T}$ cells were stimulated with TMGs or PPs (figure 1B), with the goal to expand the reactive cells and thereby facilitate their detection. Finally, the stimulated T cells were screened for recognition of the cognate TMGs and PPs.

As indicated in figure 1C, stimulated memory $\mathrm{CD} 4^{+}$ $\left(\mathrm{mCD}^{+}\right)$T cells from Patient 1 exhibited increased IFN- $\gamma$ production in response to PP1 and PP2. However, only the PP2 response could be reproduced with HPLC-purified peptides (not shown). This response was also associated with increased production of granulocyte-macrophage colony-stimulating factor (GM-CSF) and granzyme B (figure 1D). Concurrently, no significant 4-1BB upregulation was detected (not shown), suggesting that the frequency of PP2-reactive cells in the tested population was very low.

Following the IVS, memory T cells from Patients 2, 3 and 4 did not recognize any of the tumor-specific mutations (online supplemental figure 1). Cells from Patient 5 demonstrated poor expansion after the initial stimulation and thus could not be tested.

\section{A TCR expressed by memory CD4 ${ }^{+} \mathrm{T}$ cells from Patient 1 specifically recognized a neoantigen derived from mutated EED gene}

After the initial screen, PP2-reactive $\mathrm{mCD}^{+}$cells from Patient 1 were cocultured with autologous B cells pulsed with either DMSO or PP2 and then subjected to an IFN- $\gamma$ capture assay. As indicated in figure $2 \mathrm{~A}, 0.44 \%$ of $\mathrm{CD} 4^{+}$ cells produced IFN- $\gamma$ in response to PP2, while $0.03 \%$ did so in response to DMSO.
Next, captured IFN- $\gamma^{+} \mathrm{CD} 4^{+}$cells were sorted and subjected to single-cell TCR sequencing. The analysis of productive TCR sequences revealed two predominant $\mathrm{T}$ cell clones, bearing either TCR1 or TCR2 (figure 2B). Only the TCR2 was detected exclusively within the PP2stimulated IFN- $\gamma^{+} \mathrm{CD} 4^{+}$population, although at a low frequency $(3 / 32$ cells $)$.

In order to determine the function of these TCRs, allogeneic PBMCs were transduced with either TCR1 or TCR2 and then tested for recognition of individual peptides from PP2. As indicated in figure 2C, TCR1 did not recognize any of the candidate peptides, suggesting that the cells harboring this receptor were activated in a non-specific fashion. However, TCR2 recognized a 25-mer peptide (PITMQCIKHYVGNGNAINELKFHPR) derived from Embryonic Ectoderm Development gene that contained a histidine-to-asparagine mutation $\left(\mathrm{EED}^{\mathrm{H} 189 \mathrm{~N}}\right)$. TCR-VB deep sequencing of unstimulated PBMCs from Patient 1 confirmed that cells harboring this receptor were indeed derived from memory but not the naive $T$ cell subsets in the peripheral blood (online supplemental figure 2A).

Next, several analyses were performed to verify that $\mathrm{EED}^{\mathrm{H} 189 \mathrm{~N}}$ truly exhibited properties of a cancer neoantigen. First, EED gene expression was confirmed in Patient 1's freshly resected tumor sample by RNA-seq (online supplemental figure 2B). Its expression pattern could not be assessed due to the lack of simultaneous multiregion tumor sampling. However, in a WES-based clonality analysis of a single tumor biopsy, the fraction of cancer cells predicted to harbor the $\mathrm{EED}^{\mathrm{H} 189 \mathrm{~N}}$ mutation was 0.99 , indicating that this mutation was clonal in at least one tumor region.

Second, specificity of $\mathrm{EED}^{\mathrm{H} 189 \mathrm{~N}}$ recognition was verified after coculturing TCR2-transduced T cells from two unrelated donors with Patient 1's B cells that were pulsed with either $\mathrm{EED}^{\mathrm{H} 189 \mathrm{~N}}$ peptide or its WT counterpart ( PITMQCIKHYVGHGNAINELKFHPR). As indicated in figure 2D, TCR2-transduced cells from both donors recognized only the $\mathrm{EED}^{\mathrm{H} 189 \mathrm{~N}}$ in a dose-dependent manner.

Third, MHC-restricted recognition of $\mathrm{EED}^{\mathrm{H} 189 \mathrm{~N}}$ was confirmed by coculturing TCR2-transduced T cells with COS7 cells that were first transfected with pairs of plasmids encompassing all MHC-II molecules identified in Patient 1 and were then pulsed with WT or $\mathrm{EED}^{\mathrm{H} 189 \mathrm{~N}}$ 25 -mer peptides. As indicated in figure $2 \mathrm{E}$, IFN- $\gamma$ production was detected only when the COS7 cells were pulsed with $\mathrm{EED}^{\mathrm{H} 189 \mathrm{~N}}$ in presence of both HLA-DRA1*01:01 and HLA-DRB3*02:02:01.

Finally, the ability of $\mathrm{EED}^{\mathrm{H} 189 \mathrm{~N}}$ to be processed and presented on the cell surface MHC-II molecules was confirmed by coculturing TCR2-transduced T cells with COS7 transfected with plasmids encoding the HLADRA1*01:01 and HLA-DRB3*02:02:01, as well as the fulllength WT or MUT EED genes. As indicated in figure 2F, IFN- $\gamma$ production was detected only in presence of both HLA and $\mathrm{EED}^{\mathrm{H} 189 \mathrm{~N}}$ genes. 
A

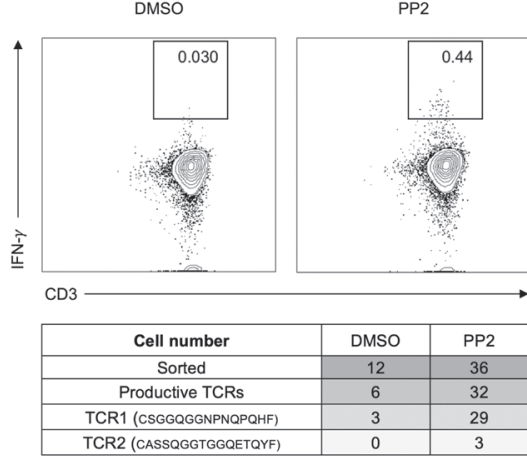

C

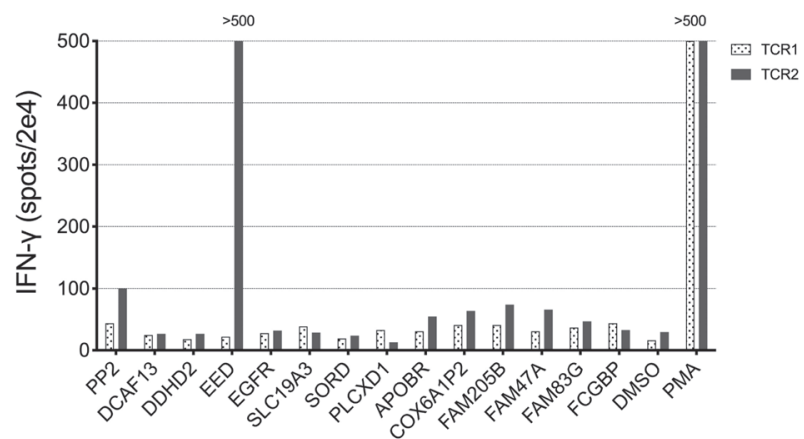

D

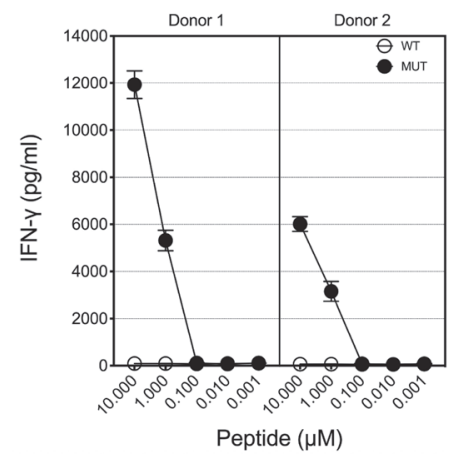

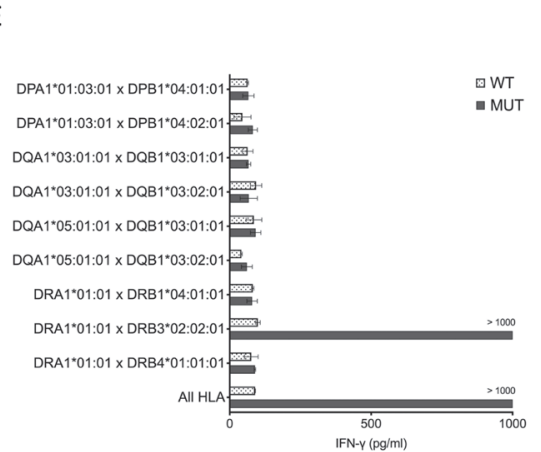

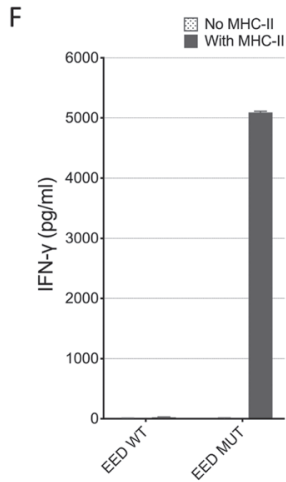

Figure 2 A TCR expressed by memory $C D 4^{+} \mathrm{T}$ cells from Patient 1 demonstrated specific recognition of tumor-specific $\mathrm{EED}^{\mathrm{H} 189 \mathrm{~N}}$ mutation. (A) PP2-stimulated $\mathrm{CD} 4^{+} \mathrm{T}$ cells were cocultured with $\mathrm{B}$ cells pulsed with DMSO or EED ${ }^{\mathrm{H} 189 \mathrm{~N}} 25$-mer peptide and then subjected to an IFN- $\gamma$ capture assay. Dot plots, gated on live CD4 ${ }^{+}$lymphocytes, indicate the percentage of IFN- $\gamma^{+} \mathrm{CD} 4^{+}$Iymphocytes in the respective cocultures. (B) The results of single-cell sorting and TCR sequencing performed on the populations indicated in (A). The number of cells in each population is listed. CDR3 sequences used to identify TCR1 and TCR2 are indicated in parentheses. (C) Allogeneic donor T cells transduced with TCR1 or TCR2 were cocultured with B cells pulsed with individual 25-mer peptides from PP2. Results of IFN- $\gamma$ ELISPOT are depicted. (D) TCR2-transduced T cells from two different donors were cocultured with autologous B cells pulsed with serial dilutions of either WT or mutated (MUT) HPLCpurified EED peptide. IFN- $\gamma$ concentration was measured in coculture supernatants by ELISA. (E) COS7 cells were transfected with all possible combinations of plasmids encoding MHC class II molecules specific to Patient 1. Next, they were pulsed for 2 hours with WT or MUT EED peptide, followed by a coculture with TCR2-transduced T cells. Results of IFN- $\gamma$ ELISA are shown. Data represent average reads from duplicate coculture wells; error bars represent SD. (F) COS7 cells were transfected with plasmids encoding full-length WT and MUT EED protein, with or without plasmids encoding MHC-II restriction elements for TCR2 (HLA-DRA1*01:01 and HLA-DRB3*02:02:01) identified in (E). This was followed by a coculture with TCR2-transduced T cells. Results of IFN- $\gamma$ ELISA are shown. Data represent average reads from duplicate coculture wells; error bars represent SD. For (D)-(F), a representative of at least two independently performed experiments is shown. HPLC, high-performance liquid chromatography; TCR, T-cell receptor; WT, wild type.

\section{DISCUSSION}

In this study, we isolated memory $\mathrm{T}$ cells from the blood of five patients with refractory glioblastoma and, following an IVS, tested them for recognition of tumorspecific mutations (SNVs and short INDELs). This led to the discovery of a rare $\mathrm{mCD} 4^{+} \mathrm{T}$ cell clone from Patient 1 that expressed an HLA-DRB3*02:02-restricted TCR, which specifically recognized a neoantigen derived from mutated EED gene $\left(\right.$ EED $\left.^{\mathrm{H} 189 \mathrm{~N}}\right)$.

EED is a ubiquitously expressed protein that serves as an essential component of polycomb repressive complex 2 (PRC2), which mediates gene silencing through histone methylation. EED deletions and inactivating EED mutations, which may hinder the PRC2 function, have been previously reported in several cancers, including glioblastoma. ${ }^{23}$ However, the oncogenic repercussions of the $\mathrm{EED}^{\mathrm{H} 189 \mathrm{~N}}$ mutation remain unknown.

Among 393 patients in the TCGA glioblastoma dataset (TCGA-GBM), EED mutations were reported in only two cases (https://www.cancer.gov/tcga). Neither of them had the EED ${ }^{\mathrm{H} 189 \mathrm{~N}}$ mutation, which thus appears unique to Patient 1 in our study. This is consistent with our previous findings in other cancer types, where the vast majority of immunogenic mutations were found to be unique and not shared among the patients. ${ }^{202425} \mathrm{~T}$ cell-mediated targeting of such mutations, which can be discovered only by performing personalized neoantigen screens, has been shown to provide durable clinical benefits in patients with select metastatic solid tumors. $^{2627}$ 
The discovery of $\mathrm{EED}^{\mathrm{H189N}}$-reactive memory $\mathrm{T}$ cells provides evidence that the immune system can mount a natural $\mathrm{T}$ cell response against a glioblastoma-specific neoantigen. Due to the limited scope of our study, the role of this response in cancer immunosurveillance remains unclear, as does the mechanism that led to its induction. It may have occurred following the in situ phagocytosis of tumor cells by the specialized APCs (eg, microglia), or following the phagocytosis of tumor cells that have emigrated from the tumor site by the APCs in the deep cervical lymph nodes.

In contrast to this endogenous $\mathrm{T}$ cell response, previous studies have successfully elicited in vivo $\mathrm{T}$ cell responses by vaccinating glioblastoma patients with peptides representing selected mutations unique to their tumors. ${ }^{4-6}$ However, such responses may not represent naturally occurring immune reactions against the tumor, and it remains uncertain whether the $\mathrm{T}$ cells that mediate them can be successfully used for therapy.

Due to its small size, this study cannot be used to accurately determine the proportion of all patients with glioblastoma who harbor neoantigen-reactive $\mathrm{T}$ cells in their blood. The low prevalence reported here ( $1 / 5$ patients) appears lower than the prevalence (5/8 patients) reported in a study that explored the same IVS method in patients with gastrointestinal malignancies. ${ }^{15}$ This discrepancy could be due to strong $\mathrm{T}$ cell suppression that characterizes glioblastoma, ${ }^{28}$ but other factors could also possibly have affected the results. For instance, the use of limited tumor biopsies for WES may have prevented the capture of all potentially immunogenic mutations due to the marked intratumoral heterogeneity that hallmarks glioblastoma. Furthermore, PBMCs from Patients 3 and 4 were obtained while the patients were receiving dexamethasone, an agent known to adversely affect the T cell function in this disease. ${ }^{29}$

In addition to the established therapeutic benefits of adoptively transferred $\mathrm{CD} 8^{+} \mathrm{T}$ cells directed against MHC-I neoantigens,${ }^{30}$ targeting MHC-II neoantigens with $\mathrm{CD}^{+}$cells can also be efficacious. For instance, administration of neoantigen-reactive $\mathrm{CD} 4^{+} \mathrm{T}$ cells to a patient with metastatic cholangiocarcinoma, a malignancy characterized by largely negative or heterogeneous MHC-II expression, ${ }^{31}$ has led to a durable, near complete tumor destruction. ${ }^{26}$ However, the mechanisms that would allow such responses in cancer types without strong MHC-II expression, including the glioblastoma, remain unclear. They may involve therapy-induced APC trafficking into the tumor with subsequent antigen cross-presentation onto MHC-I molecules, or recognition of new antigens, presented by either MHC class I or II molecules (so called "antigen spreading"), or MHC-II upregulation on the tumor cells induced by in vivo secreted IFN- $\gamma$. In support of the latter, IFN- $\gamma$ was shown to upregulate MHC-II expression and presentation of an unmutated antigen in glioblastoma cell lines. ${ }^{32}$

To establish the true prevalence and characteristics $\left(\mathrm{eg}, \mathrm{CD}^{+}\right.$vs $\mathrm{CD} 4^{+}$) of neoantigen $\mathrm{T}$ cell responses in glioblastoma, peripheral blood of a larger number of patients could be tested using the IVS, preferably in the absence of steroid treatment. Furthermore, tumor infiltrating lymphocytes, which can be successfully grown from glioblastoma specimens obtained by surgery, ${ }^{33}$ could also be tested for neoantigen recognition.

In summary, we report a successful isolation of cancer neoantigen-reactive memory $\mathrm{T}$ cells from the blood of a patient with glioblastoma, a cancer hallmarked by its immunosuppressive properties. This finding provides a rationale for further efforts to investigate neoantigen responses in these patients and to potentially develop neoantigen-directed $\mathrm{T}$ cell therapies for their treatment.

Acknowledgements The authors thank Sivasish Sindiri, Noam Levin and Yong Li for suggestions and technical support.

Contributors VL: conceptualized the project, designed and conducted experiments, analyzed data and wrote manuscript. GC, RY, BP, VH, DG, ZZ, JJG, TDP and SLG: provided resources and analyses for the study and edited the manuscript. PR and Y-CL: supervised research, edited the manuscript. SAR: conceptualized the project, supervised research and edited the manuscript.

Funding This study was funded by Intramural Research Program of the National Cancer Institute.

Competing interests None declared.

Patient consent for publication Not required.

Ethics approval Patients were enrolled on a protocol approved by the $\mathrm{NCl}$ Institutional Review Board (NCT01454596). They had provided an informed consent for all subsequent analyses of their banked blood and tumor samples, which were performed in the current study.

Provenance and peer review Not commissioned; externally peer reviewed.

Data availability statement All data relevant to the study are included in the article or uploaded as supplementary information.

Supplemental material This content has been supplied by the author(s). It has not been vetted by BMJ Publishing Group Limited (BMJ) and may not have been peer-reviewed. Any opinions or recommendations discussed are solely those of the author(s) and are not endorsed by BMJ. BMJ disclaims all liability and responsibility arising from any reliance placed on the content. Where the content includes any translated material, BMJ does not warrant the accuracy and reliability of the translations (including but not limited to local regulations, clinical guidelines, terminology, drug names and drug dosages), and is not responsible for any error and/or omissions arising from translation and adaptation or otherwise.

Open access This is an open access article distributed in accordance with the Creative Commons Attribution Non Commercial (CC BY-NC 4.0) license, which permits others to distribute, remix, adapt, build upon this work non-commercially, and license their derivative works on different terms, provided the original work is properly cited, appropriate credit is given, any changes made indicated, and the use is non-commercial. See http://creativecommons.org/licenses/by-nc/4.0/.

\section{ORCID iDs}

Vid Leko http://orcid.org/0000-0001-7883-5030

Stephanie L Goff http://orcid.org/0000-0003-3317-9804

Paul Robbins http://orcid.org/0000-0002-1260-8123

\section{REFERENCES}

1 Ostrom QT, Patil N, Cioffi G, et al. CBTRUS statistical report: primary brain and other central nervous system tumors diagnosed in the United States in 2013-2017. Neuro Oncol 2020;22:iv1-96.

2 Reardon DA, Brandes AA, Omuro A, et al. Effect of nivolumab vs bevacizumab in patients with recurrent glioblastoma: the CheckMate 143 phase 3 randomized clinical trial. JAMA Oncol 2020;6:1003-10.

3 Wen PY, Reardon DA, Armstrong TS, et al. A randomized doubleblind placebo-controlled phase II trial of dendritic cell vaccine ICT107 in newly diagnosed patients with glioblastoma. Clin Cancer Res 2019;25:5799-807. 
4 Weller M, Butowski N, Tran DD, et al. Rindopepimut with temozolomide for patients with newly diagnosed, EGFRvIIIexpressing glioblastoma (act IV): a randomised, double-blind, International phase 3 trial. Lancet Oncol 2017;18:1373-85.

5 Hilf N, Kuttruff-Coqui S, Frenzel K, et al. Actively personalized vaccination trial for newly diagnosed glioblastoma. Nature 2019;565:240-5.

6 Keskin DB, Anandappa AJ, Sun J, et al. Neoantigen vaccine generates intratumoral T cell responses in phase lb glioblastoma trial. Nature 2019;565:234-9.

7 Platten M, Schilling D, Bunse L, et al. ATIM-33. NOA-16: a first-inman multicenter phase I clinical trial of the German Neuro oncology Working group evaluating a mutation-specific peptide vaccine targeting IDH1R132H in patients with newly diagnosed malignant astrocytomas. Neuro Oncol 2018;20:vi8-9.

8 Akhavan D, Alizadeh D, Wang D, et al. Car T cells for brain tumors: lessons learned and road ahead. Immunol Rev 2019;290:60-84.

9 Brown CE, Alizadeh D, Starr R, et al. Regression of glioblastoma after chimeric antigen receptor T-cell therapy. $N$ Engl J Med 2016;375:2561-9.

10 Chuntova P, Chow F, Watchmaker PB, et al. Unique challenges for glioblastoma immunotherapy-discussions across neuro-oncology and non-neuro-oncology experts in cancer immunology. meeting report from the 2019 Sno Immuno-Oncology think tank. Neuro Oncol 2021;23:356-75

11 Bouffet E, Larouche V, Campbell BB, et al. Immune checkpoint inhibition for Hypermutant glioblastoma multiforme resulting from germline biallelic mismatch repair deficiency. J Clin Oncol 2016;34:2206-11.

12 Schalper KA, Rodriguez-Ruiz ME, Diez-Valle R, et al. Neoadjuvant nivolumab modifies the tumor immune microenvironment in resectable glioblastoma. Nat Med 2019;25:470-6.

13 Cloughesy TF, Mochizuki AY, Orpilla JR, et al. Neoadjuvant anti-PD-1 immunotherapy promotes a survival benefit with intratumoral and systemic immune responses in recurrent glioblastoma. Nat Med 2019;25:477-86.

14 Leko V, Rosenberg SA. Identifying and targeting human tumor antigens for $\mathrm{T}$ cell-based immunotherapy of solid tumors. Cancer Cell 2020;38:454-72.

15 Goff SL, Morgan RA, Yang JC, et al. Pilot trial of adoptive transfer of chimeric antigen Receptor-transduced T cells targeting EGFRvIII in patients with glioblastoma. J Immunother 2019;42:126-35.

16 Cafri G, Yossef R, Pasetto A, et al. Memory T cells targeting oncogenic mutations detected in peripheral blood of epithelial cancer patients. Nat Commun 2019;10:449.

17 Roth A, Khattra J, Yap D, et al. PyClone: statistical inference of clonal population structure in cancer. Nat Methods 2014;11:396-8.
18 Favero F, Joshi T, Marquard AM, et al. Sequenza: allele-specific copy number and mutation profiles from tumor sequencing data. Ann Oncol 2015;26:64-70.

19 Gros A, Tran E, Parkhurst MR, et al. Recognition of human gastrointestinal cancer neoantigens by circulating PD-1+ lymphocytes. J Clin Invest 2019;129:4992-5004.

20 Parkhurst MR, Robbins PF, Tran E, et al. Unique neoantigens arise from somatic mutations in patients with gastrointestinal cancers. Cancer Discov 2019;9:1022-35.

21 Paria BC, Levin N, Lowery FJ, et al. Rapid identification and evaluation of Neoantigen-reactive T-cell receptors from single cells. $J$ Immunother 2021;44:1-8.

22 Kandoth C, McLellan MD, Vandin F, et al. Mutational landscape and significance across 12 major cancer types. Nature 2013;502:333-9.

23 De Raedt T, Beert E, Pasmant E, et al. Prc2 loss amplifies RASdriven transcription and confers sensitivity to BRD4-based therapies. Nature 2014;514:247-51.

24 Deniger DC, Pasetto A, Robbins PF, et al. T-cell responses to TP53 "hotspot" mutations and unique neoantigens expressed by human ovarian cancers. Clin Cancer Res 2018;24:5562-73.

25 Cohen CJ, Gartner JJ, Horovitz-Fried M, et al. Isolation of neoantigen-specific $T$ cells from tumor and peripheral lymphocytes. $J$ Clin Invest 2015;125:3981-91.

26 Tran E, Turcotte S, Gros A, et al. Cancer immunotherapy based on mutation-specific CD4+ T cells in a patient with epithelial cancer. Science 2014;344:641-5.

27 Zacharakis $\mathrm{N}$, Chinnasamy $\mathrm{H}$, Black $\mathrm{M}$, et al. Immune recognition of somatic mutations leading to complete durable regression in metastatic breast cancer. Nat Med 2018;24:724-30.

28 Woroniecka K, Chongsathidkiet P, Rhodin K, et al. T-cell exhaustion signatures vary with tumor type and are severe in glioblastoma. Clin Cancer Res 2018;24:4175-86.

29 lorgulescu JB, Gokhale PC, Speranza MC, et al. Concurrent dexamethasone limits the clinical benefit of immune checkpoint blockade in glioblastoma. Clin Cancer Res 2021;27:276-87.

30 Tran E, Robbins PF, Rosenberg SA. 'Final common pathway' of human cancer immunotherapy: targeting random somatic mutations. Nat Immunol 2017;18:255-62.

31 Sabbatino F, Villani V, Yearley JH, et al. Pd-L1 and HLA class I antigen expression and clinical course of the disease in intrahepatic cholangiocarcinoma. Clin Cancer Res 2016;22:470-8.

32 Soos JM, Krieger JI, Stüve O, et al. Malignant glioma cells use $\mathrm{MHC}$ class II transactivator (CIITA) promoters III and IV to direct IFN-gamma-inducible CIITA expression and can function as nonprofessional antigen presenting cells in endocytic processing and CD4(+) T-cell activation. Glia 2001;36:391-405.

33 Liu Z, Meng Q, Bartek J, et al. Tumor-infiltrating lymphocytes (TILs) from patients with glioma. Oncoimmunology 2017;6:e1252894. 